\title{
Mitochondrial neurogastrointestinal encephalomyopathy
}

INSERM

\section{Source}

INSERM. (1999). Orphanet: an online rare disease and orphan drug data base. Mitochondrial neurogastrointestinal encephalomyopathy. ORPHA:298

Mitochondrial NeuroGastrolntestinal Encephalomyopathy (MNGIE) syndrome is characterized by the association of gastrointestinal dysmotility, peripheral neuropathy, chronic progressive external ophthalmoplegia and leukoencephalopathy. 